\title{
Empirical Research on Construct of Chain Store Logistics Capability System
}

\author{
Liang Xu, Shankun Wang
}

City Institute, Dalian University of Technology, Dalian, China.

Email: hary_xu@163.com,wangsk@dlut.edu.cn

Received November $22^{\text {nd }}, 2011$; revised December $29^{\text {th }}, 2011$; accepted January $7^{\text {th }}, 2012$

\begin{abstract}
Based on the review of the relevant researches on logistics capability in domestic and oversea, this paper analyses theories of chain store logistics capability and summarizes the structure of the chain store logistics capability. It puts forward that chain store logistics capability is made up of two aspects: static capability and dynamic capability, develops relevant measurement tool. The scale of the framework is reliable and valid, tested by the sample collected from the 48 domestic chain enterprises.
\end{abstract}

Keywords: Chain Store Logistics Capability; Chain Store Logistics; Logistics Service

\section{Introduction}

With the economic globalization, competition among enterprises is getting so fierce that enterprises eagerly want stronger logistics capability to deliver their products and services timely, economically. The current researches on chain store logistics capability are mostly limited to chain pharmacy business, lacking of the study to a whole for all kinds of chain stores, as each business domain has different logistics capability requirement. Based on the relevant researches review of logistics capability in domestics and oversea, this study analyses the natures and components of chain store logistics capability, develops the measurement scale, and testifies the measurements by the samples collected from the domestic chain enterprises.

\section{Logistics Capability}

Logistics capability is divided into two aspects or view: enterprise logistics capability and supply chain logistics capability. At present, there are several research achievements on logistics capability and supply chain capability in some foreign countries [1-7]. Domestic research on logistics capability is just in the beginning, mainly led by Ma Shihua, who conducted the research on the definition of logistics capability and supply chain logistics capability, and its components.

\subsection{Enterprise Logistics Capability}

Capability could be defined as a set of transaction processes, organizational flows, knowledge or techniques, that should sustain an enterprise's better performance and com- petitive advantages over its rivals [8-10].

Domestic and foreign researchers define logistics capability differently at different time and from different angles, and there is no authorized definition. Wang Ming and Feng Hao think it from the angle of operation processes that logistics capability is the capability of a logistics enterprise planning, controlling and process implementing [11] in the process of creating customer service value. Donald J. Bowersox and David J. Closs of MSU believe from the view of service and cost balance that logistics competency is a relative assessment on whether an enterprise can provide competitive customer service at a total cost as low as possible [12].

As mentioned previously, it has two characteristics [13] to understand logistics capability from above scholars:

1) Focus and view angle are different, mainly because the understanding to logistics capability is a gradual learning process.

2) Earlier work focus on the individual enterprise, which is appropriate for the market environment at that time.

\subsection{Supply Chain Logistics Capability}

As the competition intensifies day by day, the competition among enterprises has gone to the competition among the supply chains, so naturally the research aspects of enterprise logistics capability have extended to the scope of supply chain. Today, in order to survive, enterprises not only need to better use logistics resources coordinating the manufacturing and marketing activities in different locations, but also need to create an effective supply chain environment which are critical to the enterprises success. 
There are fewer studies on supply chain logistics capability from home and abroad, basically no systematic study. There is also no uniform definition of supply chain logistics capability from home and abroad currently. Ma Shihua et al. [14] think that the supply chain logistics capability, which is composed of logistics elements capability and logistics operation ability, is a comprehensive reflection to response speed, logistics cost, order accuracy, timeliness and other aspects in the entire process of logistics system, from receiving customer demand information, dealing with orders, sorting goods, transportation to final delivery to the customer. Zengfeng and Li Xiamiao [15] define that supply chain logistics capability, including objective capacity (equipment and facilities) and subjective capacity, is the capability which logistics main body successfully complete the supply chain logistics activities from purchasing raw materials to make intermediate and final products, and finally deliver products to customers by the sales network, in order to maximize the customer value and minimize the cost around the core enterprise of the supply chain. Supply chain logistics capability is not the simple sum of the members' logistics capabilities, but the overall performance of both total logistics cost and customer service from getting raw materials to final product delivery, through integrating the logistics resources of the supply chain enterprises, such as suppliers, manufacturers, distributors and retailers.

\subsection{Component Elements of Logistics Capability}

To different environment and industry, foreign and domestic scholars produced a lot of research results on component elements of the logistics capability. So far, the largest study of logistics capability was made by Global Logistics Research Team of Michigan State University (hereinafter referred to as MSU GLRT) in 1995 [16]. Through interviewing 111 companies of 17 different countries in North America, Europe and the Pacific Basin, it determines 17 general-purpose logistics capabilities from 32 possible elements of logistics capabilities and divides them into four groups: configuration ability, integration ability, agility ability and measurement ability. The study lays a solid foundation for the future research on logistics capabilities which most of the subsequent researches take this study as reference to analyze and improve according to specific industry backgrounds and environments (such as global competition and e-commerce, etc.) [16].

At present, domestic researches on logistics capability have just started, and the theoretical studies on the concept and elements of logistics capability are not deep, basically make some modifications and changes based on the research results of foreign scholars. For example, Wang Ming and Feng Hao [11] think that logistics capability usually includes the static capacity (logistics facilities and equipment, production capacity and others), dynamic capa- bility (business management and logistics management) and the integrated control capability of these two.

The above researches of domestic and foreign scholars are summarized as follows:

1) Domestic researches on logistics capability have just begun. Foreign researches have recognized the existence of logistics capabilities and researched the relationship between logistics capabilities and business performance with some preliminary results.

2) The existing researches basically revolve around a single enterprise. In another word it studies the composition and the impact on performance from the enterprise's logistics capability, not from the perspective of the entire supply chain.

3) The majority researches are case studies mainly describing the phenomenon and summarizing, lack of quantitative analysis.

4) Lack of deep research on chain store logistics capability from the angle of supply chain due to different industries and supply chain differences.

There are few studies on elements of supply chain logistics capability, and some domestic scholars improve it based on research of MSU GLRT. Ma Shihua and Chen Xiyong [14] think that logistics ability in the supply chain environment, is integrated of logistics element capability and logistics operation capacity. Logistics element capability mainly is the ability of machinery and equipment, logistics facility area (the amount of mechanical equipment or area of storage facilities, productivity, working hours and other elements); logistics operation capacity means the ability that logistics managers using logistics planning, organizing, controlling and other means to optimize the allocation of logistics resources, providing efficient and low cost services in supply chain. Zengfeng and Li Xiamiao [15] think that supply chain logistics capability is composed of objective and subjective ability. In summary, currently there are few studies on elements of supply chain logistics capability from home and abroad, and also no unified division for the elements of supply chain logistics capability, theoretical research is still lacking. Although there are some researches on assessment index system of supply chain logistics capacity, they are not systematic and in depth. In addition, specific and concrete elements to different supply chain need further study. Existing researches are mostly limited to theoretical discussion and lack of empirical research based on local Chinese. Because of the differences in different industries and supply chains, there is no deeply theoretical and empirical research on the logistics ability of chain store in the supply chain environment.

\section{Chain Store Logistics Capabilities and Component Elements}

Chain store logistics have something in common with 
logistics with its own characteristics. Based on the literature review of domestic and foreign research on the logistics capability and chain store logistics capability, this paper first effectively defines the definition of chain store logistics capability based on supply chain environment which lays a foundation for subsequent studies. The definition is as follows:

Chain store logistics capability is defined as a comprehensive reflection of response speed, logistics cost, order accuracy, timeliness and other aspects in the entire process of chain store logistics system, from receiving customer demand information, dealing with orders, purchasing goods, storing goods, sorting goods, transportation to final delivery to the customer.

Compared with other logistics, the chain store logistics has its own characteristics shown as follows:

1) Much SKU (Stock Keeping Unit, the smallest inventory unit);

2) Frequent orders;

3) Often split package and sell;

4) Prices change quickly;

5) Reverse logistics are common;

6) Products update quickly;

7) Large seasonal fluctuations in demand;

8) Guaranteed time problems.

Currently there are few domestic and international studies specifically on chain store logistics capability.

Liu Li [17] of China thinks that the logistics ability of chain pharmacies has become an important part of the core competitiveness. On the basis of foreign research results, she summed up the logistics capability and logistics activities of chain pharmacies as well as the logistics related indicators of the chain headquarters resources. The chain drugstore's logistics capability is divided into four categories: delivery capability, including the accuracy of delivery quantity, on-time delivery capability and rapid delivery capability; flexible capabilities, including rapid adjustment of drugs varieties, emergency delivery order processing and rapid adjustment of errors; cost capabilities, including reducing procurement costs, distribution costs and inventory costs; service capability, which is to resolve complaints from sub branches. Using questionnaire, she makes a comparative analysis of the logistics services and logistics capability on chain drugstores, and proposes some relevant recommendations for developing logistics capacity of chain pharmacies.

In summary, it can be seen:

1) Existing researches only focus on the logistics capability of chain pharmacies, which can't be on behalf of the entire chain store logistics capability.

2) Researches focus on the chain store logistics capability are still lacking.

3) Lacking of chain store logistics capability research in the supply chain environment.
According to the features of chain store logistics, namely small in quantity and many in variety with frequent orders and large changes in demand, also relatively common and important reverse logistics, this paper by depth interviews with managers of two well-known chain enterprise in China, thinks that, in addition to static capabilities consisted of logistics infrastructure capacity (including distribution center capacity), logistics process capability and deliver capacity which are common to general logistics, chain store logistics should highlight the dynamic capabilities which integrate, build and reconfigure internal and external capacity to adapt to rapidly changes in environment, orders and the market. Based on the above analysis, the paper thinks that the dimensions of chain store logistics capability are as follows:

Chain store logistics capability consists of static capability and dynamic capability.

1) Static capability of chain store logistics.

According to theory of enterprise capability, static capability is the inherent capacity in an enterprise. For chain store logistics, the research should be based on supply chain environment and the static capability includes facilities ability (including the distribution center capacity), logistics process ability and delivery ability.

The facilities ability is the ability of a variety of logistics handling machinery, transport and packaging tools, simple circulate processing machinery, computer, communications equipment, warehouses or distribution centers, information systems and others involved in chain store supply chain logistics activities.

The process ability includes as following: the ability to effective control and manage in the entire supply chain logistics process; total cost control ability under conditions of meeting customer service; logistics management ability to customer's changing or refunding and packing materials; risk control ability to internal and external supply chain environment; evaluation and continuous improvement ability to the entire supply chain logistics activities through internal and external benchmark or standard; the ability of providing sharing information for the costumers in supply chain; the ability to order processing; the ability to conserve goods in store.

Logistics delivery capability includes the capacity of providing safe, reliable, timely product delivery and providing consistent logistics services to customers.

2) Dynamic capability of chain store logistics.

According to theory of enterprise capability, dynamic capability is the ability to integrate, build and reconfigure internal and external capacity so as to adapt to rapid changes of environment, order and market. Based on the definition and the circumstance of chain store logistics, dynamic capability should include agile ability, match ability and integration capability. Same as the above, dynamic capability should also be based on supply chain environment. 
Agile capability includes rapid response ability to customer demand changes in all types of market and supply chains; rapid response ability to internal and external environmental changes and rapid processing ability to various types of customer complaints.

Match capability includes strategy match ability, i.e. match ability of the chain store logistics strategy to chain business strategy; business match ability, i.e. match ability of the chain store logistics to every aspect in chain store supply chain; information match ability, i.e. information match ability of the chain store logistics to every aspect in chain store supply chain; demand match ability, i.e. match ability of chain store logistics to all aspects of the supply chain.

Integration capability includes environment integration ability, i.e. internal and external environment, such as supply chain knowledge and government knowledge, policy knowledge, competitor knowledge integration; relationship integration ability, that is, the relationship integration between suppliers and corporate headquarters as well as distribution center, the relationship integration within distribution centers of the chain corporate and the integration between distribution centers and outlets; activities integration ability, which is to co-ordinate arrangements from the perspective of the entire supply chain and effectively integrate the logistics activities when developing logistics solutions to find out the best one, including store category SKU planning, goods introduction, goods shelves array, transportation and distribution planning, site selection and process planning of warehousing and distribution center, information systems planning, packaging, subsorting and distribution process planning, order processing, in store goods maintenance, providing value-added and innovative logistics services to the customers; information integration ability which uses key information sharing to make logistics activities and the entire supply chain's operations seamless; technology integration ability which optimizes the allocation and integration of available supply chain technology to make effective logistics technology solution.

In summary, based on the definition of chain store logistics capability, this paper defines dimensions of chain store logistics capability so as to avoid the common disjointing of concept definition and measurement in the current empirical research and measurement scale, the details are shown in Table 1.

\section{Research Methodology}

\subsection{The Formulation of Measuring Tool}

Combined with the development process of Churchill's [10] scale and with the references of the existing scales both at home and abroad, we give out a specific measuring tool in which some of the items are quoted from the researches carried out by MSUGLRT [18] from the Global Logistics Research Team in the state university of Michigan, Teece [19], Stank \&Lackey [20] and Wang Ming, Feng Hao [11] and Ma Shihua [14] in China with some of them extended based on the supply chain environment. The remaining items are all newly development ones which are also based on supply chain environment. The scale includes two dimensions and 23 measurement items, and for each variable it takes Level 5 scale of Likert to inquire the respondents whether the company's actual state of operation is consistent with the description. The answers cover from 1 to 5 , which means from "totally inconformity" to "fully conformity".

Before a large scale distribution of questionnaires, we firstly take a small-scale interviews about the questionnaire with nearly 10 logistical experts and related workers. All participants finish the questionnaire independently and evaluate it and provide some suggestions on modification. Then we do the pretest and give out the questionnaires to 13 chain stores in Dalian. With the feedback and CITC (Corrected Item-Total Correlation), this study re-evaluate the items in the questionnaire and delete 2 of them and then get two dimensions and 21 items.

\subsection{Data Collection and Analysis}

With another 10 newly designed items which are all related with the basic information of the investigated companies, the present study gives out the final questionnaire with 31 items. We distribute 700 questionnaires randomly in a national scale and collects 324 reliable ones with an effective collecting rate of $46 \%$. The detailed information is shown in Tables 2 and 3. The interviewees are all middle or senior managers from organizations' purchasing

Table 1. Chain store logistics capability component elements.

\begin{tabular}{ll}
\hline Component element & Specific index \\
\hline Static ability & $\begin{array}{l}\text { Logistics facility capability, } \\
\text { delivery center capability etc. } \\
\text { Logistics processing capability } \\
\text { Logistics delivery capability }\end{array}$ \\
& Agile ability \\
Dynamic ability & Matching ability \\
& Integrated ability \\
\hline
\end{tabular}

Table 2. Unit type.

\begin{tabular}{ccc}
\hline Unit type & Number & Percentage \\
\hline State-owned & 77 & 23.8 \\
Private enterprise & 206 & 63.6 \\
Foreign-owned & 41 & 12.6 \\
Total & 324 & 100.0 \\
\hline
\end{tabular}


Table 3. Enterprise scale.

\begin{tabular}{ccc}
\hline Enterprise scale & Number & Percentage \\
\hline Small business & 63 & 19.4 \\
Medium-sized company & 52 & 16.1 \\
Large enterprise & 209 & 64.5 \\
Total & 324 & 100.0 \\
\hline
\end{tabular}

center, logistical center, distribution center, storefront and so on. Due to the limited ability, the questionnaires are given out to 48 national chain enterprises, of which $80 \%$ are from the northeast part of china, including the chain pharmacies, convenience stores, large department stores, cosmetic shops, fast food restaurant, sports shops, computer and appliance stores, shoe stores, crafts shops, the grocery stores, etc., covering most of the chain store forms. Through the analysis of variance, there is no significant difference on the perception of chain logistics capability among those variables.

The questionnaire takes the level 5 scale of Likert in which the mean of the variable is 3.81. As shown in Table 4 , it shows that in china now the logistics capability of chain store has surpass the middle level but does not reach a very high degree.

\subsection{Reliability Test}

Reliability refers to the stability and consistency of a measure. To test the reliability of a scale is to test the internal consistency with the Cronbach Coefficient as the main index. When we test the reliability of the chain store logistics capability in the questionnaire, the Cronbach a value in both of the two dimensions are all 0.914 greater than 0.8 , which means this scale has a preferable reliability. At the same time, the overall Cronbach a value in the above two dimensions is 0.937 larger than 0.8 , which shows that this scale has an agreeable inside consistency and a good reliability.

\subsection{Validity Inspection}

After testing the reliability of the scale, the validity inspection is followed by using two methods: the convergence validity and the distinguish validity. This paper first makes the preliminary validity inspection by exploratory factor analysis. In this study the value of KMO is 0.941 and the chi-square is 2455.479. The concomitant probability given out by the Bartlett inspection is 0.000 . The measuring result shows that the data is suitable for factor analysis. By rotating, it extracts two factors and for each of them it covers different values of variables whose factor loading is greater than 0.4 but in other dimensions the factor loading is less than 0.4 , more details are shown in Table 5. The maximum value of each item in a single
Table 4. Variables and dimensions.

\begin{tabular}{|c|c|c|c|c|c|}
\hline Variables & Dimensions & $\begin{array}{l}\text { Mean } \\
\text { value }\end{array}$ & $\begin{array}{l}\text { Standard } \\
\text { deviation }\end{array}$ & $\begin{array}{l}\text { Mean } \\
\text { value }\end{array}$ & $\begin{array}{l}\text { Standard } \\
\text { deviation }\end{array}$ \\
\hline \multirow{2}{*}{$\begin{array}{l}\text { Logistics } \\
\text { capability }\end{array}$} & Static ability & 3.80 & 0.63 & \multirow{2}{*}{3.81} & \multirow{2}{*}{0.58} \\
\hline & $\begin{array}{l}\text { Dynamic } \\
\text { ability }\end{array}$ & 3.83 & 0.61 & & \\
\hline
\end{tabular}

Table 5. Exploratory factor analysis of chain store logistics capability.

\begin{tabular}{|c|c|c|}
\hline Item & Factor 1 & Factor 2 \\
\hline SCF01 & & 0.555 \\
\hline SCP02 & & 0.617 \\
\hline $\mathrm{SCP} 03$ & & 0.713 \\
\hline SCP04 & & 0.746 \\
\hline $\mathrm{SCP} 05$ & & 0.755 \\
\hline SCP06 & & 0.597 \\
\hline SCP07 & & 0.704 \\
\hline SCP08 & & 0.632 \\
\hline SCP09 & & 0.483 \\
\hline SCD11 & & 0.646 \\
\hline DCF12 & 0.512 & \\
\hline DCF14 & 0.501 & \\
\hline DCF15 & 0.587 & \\
\hline DCF16 & 0.67 & \\
\hline DCF17 & 0.653 & \\
\hline DCF18 & 0.68 & \\
\hline DCI19 & 0.714 & \\
\hline DCI20 & 0.679 & \\
\hline DCI21 & 0.664 & \\
\hline DCI22 & 0.644 & \\
\hline DCI23 & 0.664 & \\
\hline
\end{tabular}

dimension is 0.755 , the minimum 0.501 , the average is 0.5 and at the same time in other dimensions the value of factor loading is less than 0.4 which means this scale has a good convergent validity and discriminative validity.

This study proves that there is a consistency between the dimension summarized through theory and the one tested in the reality by doing the validity inspections and the exploratory factor analysis.

The convergent validity and discriminative validity of the scale is tested in the previous exploratory factor analysis. In the following part this paper uses the confirmatory factor analysis to test those two validities. 
In order to further explore the structure of chain store logistics capability, this paper tests or verify a series of structure models to confirm the model we got has a higher goodness of fit. There are three kinds of models to choose: 1) single factor model, considering the 21 items of chain store logistics capability as one factor; 2) double factor model of first-order and the dimensions are unrelated with each other; 3) double factor model of first-order but the dimensions are related with one another and model 3 is used in the present study.

This paper plans to take the commonly used inspection index to test the scale. As the (Chi-Square) $\chi^{2} / \mathrm{df}$ is less than 5 and the value is smaller, NFI, GFI, CFI, AGFI larger than 0.9 and RMSEA, RMR less than 0.05, it then concludes this model has a better fitting effect; as NFI, GFI, CFI, AGFI are between 0.8 and 0.9 and RMSEA is less than 0.1, it concludes the fitting effect is acceptable $[21,22]$. The analysis results are shown in Table 6.

As shown in Table 6, the value of (Chi-Square) $\chi^{2} / \mathrm{df}$ is 2.38 less than 5 and values in other models; GFI, AGFI, NFI, CFI greater than 0.8 and values in other models; RMSEA less than 0.1, RMR less than 0.05, which indicates the model taken in this research is the best one to test the capability of chain store logistics. The loading value of these 21 items in each of their dimensions is between 0.59 and 0.77 and there is no overlap among these items which shows the items of chain store logistics capability have a better effective convergent validity. The correlation coefficient between the two dimensions is 0.85 lower than the critical point 0.9 , which shows that they have an effective discriminative validity. The above indexes prove that this scale has a good fitting capability.

What's more as shown in Table 7, the $\mathrm{P}$ value is 0.0 , as LISREL is very sensitive to the sample size, many researches choose to use the (Chi-Square) $\chi^{2} / \mathrm{df}$ as an indicator for the fitting degree. The ratio of chi-square and degree of freedom in this model is 2.267 less than 5 . RMSEA is 0.077 less than the standard value 0.08 and the fitting index GFI, AGFI, CFI, NFI are 0.95, 0.91, $0.97,0.95$ which are all greater than 0.9 suggested by those researches. This means confirmatory factor analysis model is quite consistent with the fitting degree. So we can conclude that this scale has an effective convergent validity.

As shown in Table 8, the correlation coefficient between the dimensions are all less than the reliability coefficient respectively which means this scale is consistent with the discriminative validity. As the chain store logistics capability has only two first-order factors, it should not carry out a second-order factor analysis [23].

In conclusion, the scale used in the present study has a good reliability and an effective validity, which proved this further that the chain store logistics capability can be divided into two factors the static chain store logistics capability and the dynamic one. So we call this scale as the CLC scale.

\section{Conclusion and Recommendations for Future Research}

Based on a literature review both at home and abroad and

Table 6. Comparative analysis of chain store logistics model structure.

\begin{tabular}{|c|c|c|c|c|c|c|c|c|c|}
\hline Model & Chi-Square & df & Chi-Square/df & GFI & AGFI & NFI & CFI & RMSEA & RMR \\
\hline Model 1 & 606.75 & 189 & 3.21 & 0.8 & 0.76 & 0.94 & 0.96 & 0.097 & 0.062 \\
\hline Model 2 & 554.82 & 189 & 2.94 & 0.82 & 0.77 & 0.93 & 0.95 & 0.091 & 0.27 \\
\hline Model 3 & 447.18 & 188 & 2.38 & 0.85 & 0.81 & 0.95 & 0.97 & 0.077 & 0.046 \\
\hline
\end{tabular}

Table 7. Analysis of chain store logistics competency confirmatory factor.

\begin{tabular}{cccccccc}
\hline Chi-Square & df & Chi-Square/df & GFI & AGFI & NFI & CFI & \\
\hline 426.18 & 188 & 2.267 & 0.95 & 0.91 & 0.95 & 0.97 \\
\hline
\end{tabular}

Table 8. Correlation coefficients.

\begin{tabular}{ccc}
\hline & Static ability & Dynamic ability \\
\hline Static ability & 1.000 & 1.000 \\
Dynamic ability & $0.758^{* *}$ & 0.905 \\
Cronbach ability & 0.905 & 0.905 \\
\hline
\end{tabular}

Note $1^{* *}$ indicate double tail test, obvious at 0.01 confidence level. 
the interviews on chain store staff, combined with features of chain store logistics, this paper tries to give the chain store logistics capability a clear definition. At the same time this paper follows the rules which use the definition of variables to define the constitution and divides the chain store logistics capability into two dimensions: the static one and the dynamic one. Through the theory studies, empirical analysis and the reliability and validity test, this paper also designs a scale of chain store logistics capability which has good reliability and validity and hopes that it can provide a testing tool and an assessment method for chain store logistics capability in china.

Although this paper puts forward some innovative academic ideas and makes some academic contributions, there are also some limitations, the details are as follows:

1) It can make this study more persuasive by enlarging the sample size and improving the precision of the statistical analysis, although the sample size in this research has already been up to the requirements of statistical analysis.

2) The chain stores selected in the samples are from part of the provinces in china and most of them locate in the northeast area, which may influence our conclusion. The future study should collect chain store data from different areas to verify the index system.

3) The research has covered most of the chain store forms. However, to make the study more general it is necessary to choose other chain store forms to do further empirical researches. For example, as the present situation limitation of the chain stores in china, the chain store logistics selected in this study are mainly self-owned. So we need to expand the scope of investigation and enlarge the number of chain stores, especially further exploration on those chain stores which outsource their logistics services.

\section{REFERENCES}

[1] E. A. Morash, C. L. M. Droge and S. K. Vickery, "Strategic Logistics Capability for Competitive Advantage and Firm Success," Journal of Business Logistics, Vol. 17, No. 1, 1996, pp. 1-22.

[2] M. Zhao, C. Droge and T. P. Stank, "The Effects of Logistics Capabilities on Firm Performance: Customer-Focused versus Information-Focused Capabilities," Journal of Business Logistics, Vol. 22, No. 2, 2001, pp. 91-107. doi:10.1002/j.2158-1592.2001.tb00005.x

[3] S. E. Fawcett, L. L. Stanley and S. R. Smith, "Developing a Logistics Capability to Improve the Performance of International Operations," Journal of Business Logistics, Vol. 18, No. 2, 1997, pp. 101-127.

[4] R. Amit and P. J. H. Schoemaker, "Strategic Assets and Organizational Rent," Strategic Management Journal, Vol. 14, No. 1, 1993, pp. 33-46. doi:10.1002/smj.4250140105

[5] D. J. Collis, "Research Note: How Valuable Are Organ- izational Capabilities?" Strategic Management Journal, Vol. 15, No. 1, 1994, pp. 143-152.

doi: $10.1002 /$ smj. 4250150910

[6] R. Hayes, S. C. Wheelwright and K. B. Clark, "Dynamic Manufacturing: Creating the Learning Organization," Free Press, New York, 1988.

[7] S. Olavarrieta and A. E. Ellinger, "Resource-Based Theory and Strategic Logistics Research," International Journal of Physical Distribution and Logistics Management, Vol. 27, No. 9-10, 1997, pp. 559-587. doi:10.1108/09600039710188594

[8] J. Barney, "Firm Resources and Sustained Competitive Advantage," Journal of Management, Vol. 17, No. 1, 1991, pp. 99-120. doi: $10.1177 / 014920639101700108$

[9] C. K. Prahalad and G. Hamel, "The Core Competence of the Corporation," Harvard Business Review, Vol. 68, 1990, pp. 79-91.

[10] M. A. Hitt and R. D. Ireland, "Corporate Distinctive Competence, Strategy, Industry, and Performance," Strategic Management Journal, Vol. 6, No. 3, 1985, pp. 273-293. doi: $10.1002 / \mathrm{smj} .4250060307$

[11] F. Wangmin, "The Research on Chinese Logistics Industry Development Policy," China Planning Press, Beijing, 2002.

[12] D. J. Bowersox and D. J. Closs, "Logistics ManagementSupply Chain Process Integration," China Machine Press, Beijing, 2002.

[13] J. M. Cai and F. Zeng, "The Concept, Characteristic and Influence Factor of Supply Chain Logistics Capability," Logistics Science and Technology, Vol. 29, No. 127, 2005, pp. 88-91.

[14] P. J. Daughery and P. H. Pittman, "Utilization of TimeBased Strategies: Creating Distribution Flexibility/Responsiveness," International Journal of operations and Production Management, Vol. 15, No. 2, 1995, pp. 54-60. doi:10.1108/01443579510080418

[15] X. Q. Liu, "The Architecture and Optimization of Supply Chain Logistics Capability," Huazhong University of Science and Technology, Wuhan, 2006.

[16] S. H. Ma and X. Y. Chen, "The Research on Logistics Capability Components and Features in Supply Chain Environment," Management Journal, Vol. 1, No. 1, 2004, pp. 107-111.

[17] F. Zeng and X. M. Li, "Exploration of Supply Chain Capability," Logistics Science and Technology, Vol. 28, No. 121,2005 , pp. 69-72.

[18] S. H. Ma, Q. X. Meng, "The Research Status and Development Trends of Supply Chain Capability," Computer Integrated Making System, Vol. 11, No. 3, 2005, pp. 301307.

[19] J. F. Jiang and Z. X. Liu, "The Discrimination and Analysis of Three Kinds of Important Capability in Logistics Enterprise," Logistics Science and Technology, No. 7, 2005, pp. 18-21.

[20] L. Liu, "The Research on Logistics Service and Capability of Chain Drugstore," Economic Issue, Vol. 5, 2008, pp. 66-69.

[21] GLRT at Michigan State University, "World Class Logis- 
tics: The Challenge of Managing Continuous Change," Council of Logistics Management, Oakbrook, 1995.

[22] D. J. Teece, G. Pisano and A. Shuen, "Dynamic Capabilities and Strategic Management," Strategic Management Journal, Vol. 18, No. 7, 1997, pp. 509-533. doi:10.1002/(SICI)1097-0266(199708)18:7<509::AID-S MJ882>3.0.CO;2-Z

[23] T. Stank and C. Lackey, "Enhancing Performance through Logistical Capabilities in Mexican Maquiladora Firms," Journal of Business Logistics, Vol. 18, No. 1, 1997, pp. 91-123.

[24] J. H. Steiger, "Structure Model Evaluation and Modification: An Interval Estimation Approach," Multivariate Be- havioral Research, Vol. 25, No. 2, 1990, pp. 173-180.

[25] P. M. Bentler and D. G. Bonett, "Significance Tests and Goodness of Fit in the Analysis of Covariance Structures," Psychological Bulletin, Vol. 88, No. 3, 1980, pp. 588-606. doi:10.1037//0033-2909.88.3.588

[26] C. Fornell and D. F. Larcker, "Evaluating Structural Equation Models with Unobservable and Measurement Errors," Journal of Marketing Research, Vol. 18, No. 1, 1981, pp. 39-50.

[27] J. T. Hou, Z. L. Wen and Z. J. Cheng, "The Model and Application of Structural Equation," Educational Science Press, Beijing, 2008. 